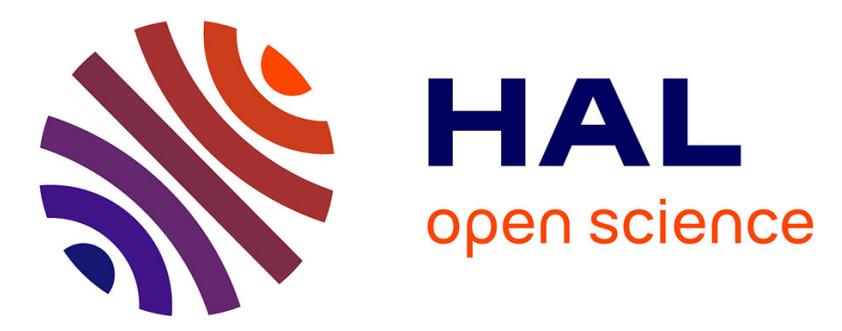

\title{
Intra-and inter-individual variability in the mechanical properties of the human skin from in vivo measurements on 20 volunteers
}

Emmanuelle Jacquet, Jérôme Chambert, Julien Pauchot, Patrick Sandoz

\section{- To cite this version:}

Emmanuelle Jacquet, Jérôme Chambert, Julien Pauchot, Patrick Sandoz. Intra-and inter-individual variability in the mechanical properties of the human skin from in vivo measurements on 20 volunteers. Skin Research and Technology, 2017, 10.1111/srt.12361 . hal-01501644

\section{HAL Id: hal-01501644 \\ https://hal.science/hal-01501644}

Submitted on 4 Apr 2017

HAL is a multi-disciplinary open access archive for the deposit and dissemination of scientific research documents, whether they are published or not. The documents may come from teaching and research institutions in France or abroad, or from public or private research centers.
L'archive ouverte pluridisciplinaire HAL, est destinée au dépôt et à la diffusion de documents scientifiques de niveau recherche, publiés ou non, émanant des établissements d'enseignement et de recherche français ou étrangers, des laboratoires publics ou privés. 


\title{
Intra- and inter-individual variability in the mechanical properties of the human skin from in vivo measurements on 20 volunteers
}

\author{
E. Jacquet ${ }^{\mathrm{a}}$, J. Chambert ${ }^{\mathrm{a}}$, J. Pauchot ${ }^{\mathrm{b}}$, P. Sandoz ${ }^{\mathrm{a}}$ \\ ${ }^{a}$ Univ. Bourgogne Franche-Comté, FEMTO-ST Institute, CNRS/UFC/ENSMM/UTBM, Department of Applied \\ Mechanics, Besançon, France \\ ${ }^{b}$ Univ. Bourgogne Franche-Comté, Centre Hospitalier Régional Universitaire, Service de Chirurgie Orthopédique, \\ Traumatologique et Plastique, CHRU J. Minjoz, Besançon, France \\ Corresponding author: Dr. Emmanuelle Jacquet \\ e-mail: emmanuelle.jacquet@univ-fcomte.fr \\ Phone: +33 381666019 , Fax: +33 381666700 \\ 24, rue de l'Epitaphe, 25000 Besançon, France \\ Number of pages: 16 - Number of table: 1
}

\begin{abstract}
Background/Purpose: The mechanical properties and behavior of the human skin in vivo are of medical importance, particularly to surgeons who have to consider the skin extension capabilities in the preparation of surgical acts. Variable data can be found in literature that result from diverse kinds of tests (in vivo, ex vivo, post-mortem) performed with different instruments.

Methods: This paper presents the results of in vivo measurements performed on a cohort of 20 healthy volunteers with an ultralight homemade uniaxial extensometer. Different anatomical zones were explored under different directions of solicitation in order to document inter- and intra-individual variability as well as skin anisotropy.

Results: The experimental data obtained are fitted with a phenomenological exponential model allowing the identification of three parameters characteristic of the tested skin behavior. These parameters can be related to the concept of skin extensibility used by surgeons.

Conclusion: The inter- and intra-variability observed on that cohort confirms the need for a patient-specific approach based on the in vivo measurement of the mechanical behavior of the human skin of interest. Even the direction of higher skin stiffness is found to be individualdependent. The capability of the extensometer used in this study to fulfill such measurement needs is also demonstrated.
\end{abstract}

Keywords: Mechanical skin behavior, Extension tests, In vivo measurements, Variability, Hyperelastic behavior, Characteristic parameters 


\section{Introduction}

The human skin constitutes an interface between the human body and the surrounding environment. It stands for a chemical and mechanical protection against external adversities. When the skin is damaged either accidentally or surgically, the skin continuity has to be reconstructed This is especially problematic when a significant area of skin has been lost, in case of skin tumors for instance, since the surrounding skin has to be extended to cover the wound [1]. In such circumstances, the mechanical properties of the skin correspond to a key-characteristic determining up to which rate the skin can be stretched. The closing of the wound will indeed be much easier with a soft and elastic skin than with a rigid and inextensible skin [2]. Surgeons are used to appraise empirically the skin elasticity and the subcutaneous fat layer thickness by applying manually a pinch test $[3,4]$. Such a qualitative evaluation is subjective and depends on surgeon's know-how. From a clinical point of view, the pinch test is used to determine the best suited surgical act, notably to spread the closing efforts on the right area of surrounding skin to optimize wound healing. In case of excessive skin extension, internal fluid flow can be disturbed up to induce complications such as necrosis. In this context, the development of objective tools able to specify the mechanical properties of the skin would make this decision process more rational, safer, and thus beneficial to the patient.

Numerical simulations of the wound closing efforts have been proposed but they are highly dependent on the mechanical skin behavior $[5,6,7,8]$. The latter is known to depend on both individuals and body zones and no standardized data can be used satisfactorily. It is therefore necessary to characterize the mechanical skin behavior in an individualized and localized way to determine the actual parameters to take into account $[9,10]$. Once the actual mechanical parameters are determined, numerical simulations of the efforts and of the stress fields induced by diverse surgical options can help surgeons in deciding the best surgical strategy for each act and patient. This paper presents the results of such mechanical tests performed on a cohort of healthy volunteers with a light and portable instrument described elsewhere [11]. We highlight the intra-individual and inter-individual variability also observed in suction tests [12], in out-ofplane deformation tests [13], and in dynamic indentation [14]. We also interpret those results by means of three parameters characterizing the tested skin mechanical behavior, thus providing objective parameters to help surgeons in their decision processes. 


\section{Material and Methods}

\subsection{Portative extensometer for in vivo measurement}

The mechanical tests were carried out using the tensile testing device shown in Fig. 1 and developed specifically for measurements on the human skin in vivo. It is a portable lightweight extensometer usable without stand on most anatomical zones. It consists of a rectangular frame to which are attached an electric motor, two guide columns and two crossheads; one fixed, the other mobile and each comprising two tabs. Measurements are performed on the central tab whereas the secondary surrounding tab serves for guarding by protecting the measuring zone from lateral and peripheral forces. The central and guarding tabs are moved together and the extension is applied to both the measuring zone and to the surrounding skin. The movable crosshead is driven by an electric motor whose rotary movement is transformed into translation by a screw-nut system. The movable crosshead is equipped with a specific bronze-berrylium beam which serves as force sensor on which strain gauges are stuck at the location where the bending deformation is maximal. The device is supplemented by a LVDT-type displacement sensor that provides the moveable tab position. The device, servo-controlled in either force or displacement, allows the performance of large extensions tests on the human skin in vivo. The gap between the fixed and mobile tabs ranges from $30 \mathrm{~mm}$ to $45 \mathrm{~mm}$, allowing a maximum extension of $50 \%$. The maximal force that can be applied is limited to $5 \mathrm{~N}$. Diverse kinds of controlled tests are permitted, quasistatic, harmonic, impulse or relaxation tests, on most of the human sites in vivo with a maximum displacement speed of $1 \mathrm{~mm} / \mathrm{s}$. The device is light enough to work as a standalone instrument and is consistent with standards and biomedical requirements. The secondary, guarding tabs minimize the parasitic effects of the area surrounding measurement zone, thus making the stress field homogeneous as in a classic tensile test. Full description of the device used can be found in [11].

\subsection{Volunteer cohort and complementary biological parameter assessment}

The mechanical tests were carried out in the Department of Applied Mechanics of FEMTOST Institute at several anatomical sites (forearm, abdomen, thigh and calf) of 20 recruited volunteers. The subjects are 12 men, 8 women distributed between 18 and 57 years. Their body mass index (BMI) is between 18 and 29. The tested skin thickness was measured at the Center for Studies and Research on the Integument of the regional University Hospital Center of Besançon with 


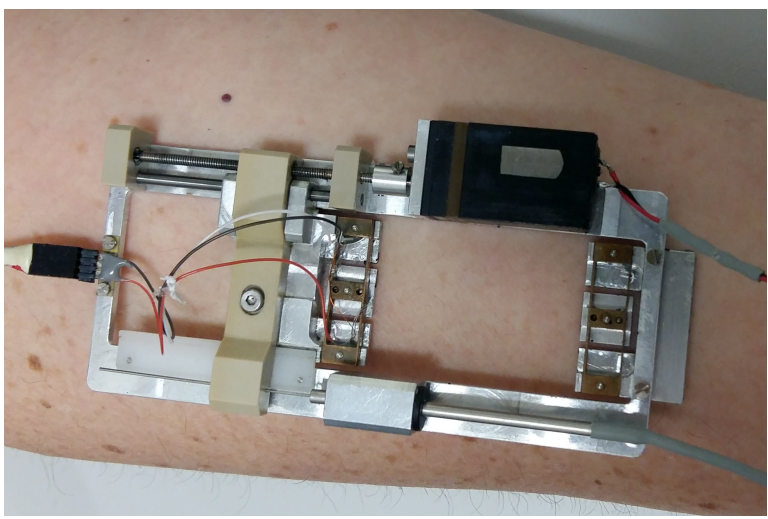

Figure 1: Extensometer device stuck on forearm

a high-resolution ultrasound skin Dermcup Atys ${ }^{\circledR}$. For each measurement, three ultrasound images were taken and for each image three thickness measurements were carried out. For each site, the average value of the nine measurements is taken. The average thickness is $1.96 \pm 0.26 \mathrm{~mm}$ on the abdomen, $1.6 \pm 0.36 \mathrm{~mm}$ on the thigh, $1.28 \pm 0.14 \mathrm{~mm}$ on the calf and $1.39 \pm 0.30 \mathrm{~mm}$ on the forearm. These thickness values are similar to the ones in [15]. Additional measurements of stratum corneum hydration rate were taken using a Corneometer ${ }^{\circledR}$ CM 825 (Courage and Khazaka electronic $\mathrm{GmbH}$ ) evaluating the dielectric capacitance of the skin surface layers (epidermis + stratum corneum). After a rest of 15 minutes in a room at constant temperature and humidity and before the tensile tests, three successive measurements of the hydration index of the tested zones were performed.

\subsection{Protocol and experiments}

The tests followed the rules imposed by the Hygiene and Safety Service of the University. Prior to measurements, the test protocol is submitted in full details to volunteers who give their written approval. It involves the following steps :

- A preparation of the tested area. The area should not contain any hair and not being hydrated and treated with a cream since the day before the test.

- A rest period in an elongated position with straight legs, arms alongside the body and acclimatization of the skin to the air at constant temperature and humidity of 15 minutes during which the subject answers the questionnaire (age, BMI and so on). 
- The measuring of the hydration index of the area to be tested.

- The mechanical tests according to the procedure detailed below.

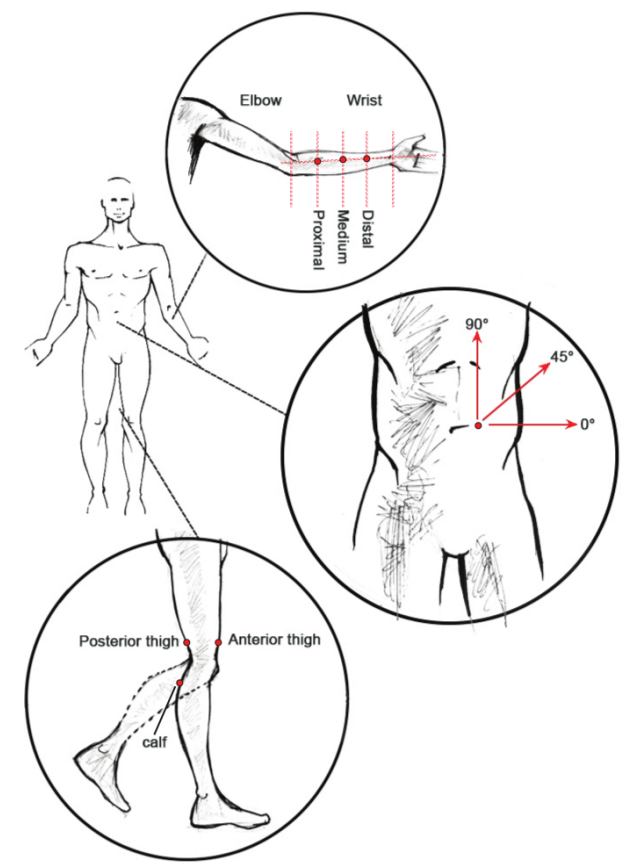

Figure 2: Anatomical areas that were studied. Distal, middle and proximal forearm, abdomen and anterior or posterior thigh and calf.

The volunteer is lying down in order to present the area of interest steady and horizontal upwards.

The zone is defined based on the cranio-caudal and medio-lateral lines and precise anatomical landmarks : At the front face of the arm, three zones are defined on the forearm to 1/4 (distal forearm), 1/2 (middle forearm) and 3/4 (proximal forearm) of the wrist - elbow segment (Fig. 2). At the abdomen, the center of the tested area is offset from the cranio-caudal line a third from the navel-iliac crest segment (Fig. 2). At the leg, a front thigh area is about $10 \mathrm{~cm}$ above the knee, a calf area at the widest area of the calf and a back thigh area to the back of leg area about $10 \mathrm{~cm}$ above the knee bend (cf Fig. 2). The solicited axes are also identified from the cranio-caudal line : At the arm, the $0^{\circ}$-axis is along the arm. At the abdomen, the $90^{\circ}$-axis is parallel to the cranio-caudal line. At the leg, the $0^{\circ}$-axis is along the leg. The tabs of the extensometer are attached to the skin surface thanks to a surgical glue. Upload consists of three cycles followed by a holding time to take into account the preconditionning of the skin [12]. This phenomena 
has been widely discussed by several authors $[16,14]$. After three repeating cycles a steady state tends to be reached and the material behavior is more reproducible. In the following results, only the third loading sequence has been analyzed. The loading rate remains constant, equal to $1 \mathrm{~mm} / \mathrm{s}$. The test is then repeated until a maximum of $42 \%$ of extension when the elasticity of the skin allows. The take-off of the device is immediate and painless. The skin is then cleaned with alcohol and the glue residues on the tabs of the device are removed with a solvent and then the tabs are rinsed with alcohol. This process is repeated for each loading direction.

\subsection{Data analysis}

The raw data are obtained by measuring the force recorded on the measuring tab when it is moved during the test. Incremental time, command, displacement and force data are registered during the whole test. The raw data are processed using a Butterworth filter operating a moving average on the force data obtained for an imposed displacement speed. An order two lowpass digital Butterworth filter with normalized cutoff frequency $0.1 \mathrm{~Hz}$ is successively used in the forward and backward directions [17]. Filtering the raw data is necessary particularly for low levels of force.

We neglect the existing shear stress due to the fact that the skin is loaded on a surface and not directly on the section of the considered area. The stress field in the measuring area is then defined by the unique component $T$ of the first Piola-Kirchhoff stress tensor in the traction direction,

$$
T=\frac{F}{A_{0}}=\frac{F}{d \cdot e_{0}},
$$

where $F$ is the measured force, $A_{0}$ is the initial cross-sectional area of the specimen defined by the product of the measuring tab width $d$ and the skin thickness $e_{0}$ at the beginning of the test.

The uniaxial engineering strain $\varepsilon$ in the loading direction is obtained from the imposed distance between the two main tabs, i.e the displacement of the tab whose movement is controlled,

$$
\varepsilon=\frac{\Delta L}{L_{0}}=\frac{L-L_{0}}{L_{0}},
$$

where $\Delta L$ is the displacement of the measuring tab; $L$ and $L_{0}$ are, respectively, the actual and initial length between the two tabs.

For the characterization of the mechanical behavior of soft tissues, the phenomenological approach consists in fitting mathematical expressions to experimental stress-strain curves. In the literature, the nonlinear behavior of skin tissue is mostly characterized by an exponential form of 
stress-strain relationship when only the elastin fibers are being stretched for small deformations, and by a power equation when the collagen fibers are being mainly loaded for large deformations [18]. For various elastin-dominant soft tissues, Fung [19] has shown a linear relationship between the stress $T$ and the tangent modulus $\mathrm{d} T / \mathrm{d} \varepsilon$, which leads to an exponential form of the stressstrain curve. Fung [19] has also proposed a piecewise linear function of $\mathrm{d} T / \mathrm{d} \varepsilon$ versus $T$ curve in order to distinguish the initial phase at elastin-dominant from the final one at collagen-dominant. For the sake of simplicity, we propose the use of an exponential equation for the whole stressstrain curve :

$$
T=A[\exp (B \varepsilon)-1]
$$

where $A$ and $B$ are fitting parameters.

By following Raghavan et al. [20]'s analysis on aorta, we propose to identify three physical parameters useful for the surgeon (see Fig. 3) :

- the initial tangent modulus $E_{1}$ (initial slope of the stress-strain curve) which corresponds to the contribution of the elastin fibers alone ;

- the final tangent modulus $E_{2}$ (final slope of the stress-strain curve) which stands for the combined contribution of elastin and collagen fibers ;

- the intercept $\varepsilon_{T}$ of the strain-axis with the final slope of the stress-strain curve.

The three physical parameters are determined by applying the following consecutive steps (see Fig. 3). First, the values of parameters $A$ and $B$ in Eq. (3) are fitted to experimental stressstrain data by using an inverse method based on Levenberg [21] - Marquardt [22] algorithm. The coefficient of determination $R^{2}$ is computed to quantify the goodness-of-fit. Second, the value of $E_{1}$-parameter is determined by fitting the first values of the stress-strain experimental curve with a linear regression technique, and computing the resultant slope. Third, the value of $E_{2}$ parameter is obtained from the derivative of Eq. (3) taken at the strain ultimate value. Fourth, the value of $\varepsilon_{T}$-parameter is determined by intercepting the strain-axis with the final tangent of the stress-strain curve.

According to [23] and [24], a typical stress-strain curve for in vivo skin in uniaxial tension, as shown in Fig. 3, can be separated into three consecutive parts : the initial phase (the elastin fibers are stretched and the collagen fibers orientate into the direction of extension), the transitional 


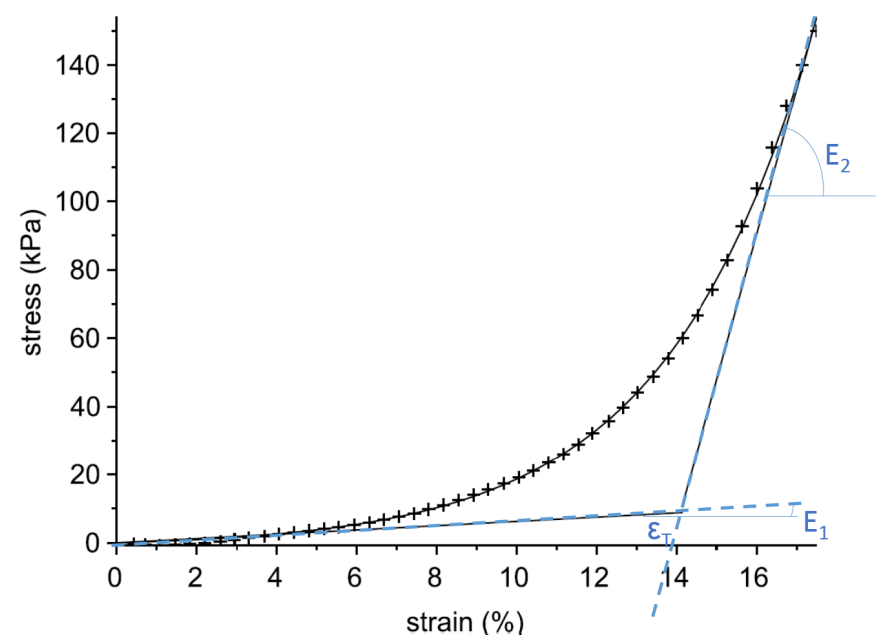

Figure 3: Experimental data (cross symbols) obtained on a right forearm sollicited along $0^{\circ}$-axis; corresponding exponential model fit (solid line) from Eq. (3) and geometrical description of physical parameters. Obtained values : $A=1.3 \mathrm{kPa}$, $B=27.4, E_{1}=62.7 \mathrm{kPa}, E_{2}=4250 \mathrm{kPa}, \varepsilon_{T}=13.9 \%$. and $R^{2}=99.95 \%$

phase (the collagen fibers straighten out gradually that entails the nonlinear behavior of skin and an increasing stiffness) and the final phase (the collagen fibers fully aligned into the direction of extension cause the linear behavior for high stresses). The $\varepsilon_{T}$-parameter corresponds to a specific state within the transition phase. Gibson et al. [25] have interpreted this parameter as a measure of extensibility of the skin in that direction. As in [26], this state defines a physiological load limit that enables to maintain the integrity of the skin. The $\varepsilon_{T}$-parameter can be interpreted as the strain threshold that should not be exceeded during a surgery to prevent medical complications. Considering the anisotropy of the skin behavior, Gibson et al. [25] have shown the close correlation between the direction of minimum $\varepsilon_{T}$-parameter value and Langer's line [27]. That confirms the interest of $\varepsilon_{T}$-value for the surgeon.

\section{Results and discussion}

Most of the results are presented by stress-strain curves as previously explained with physical parameters presented in the corresponding tables.

\subsection{Model relevance for measurement on human skin}

In order to analyse the experimental results, the constitutive parameters of the mathematical model (see Eq. (3)) have been identified on several stress-strain curves and collected in tab. 1. 


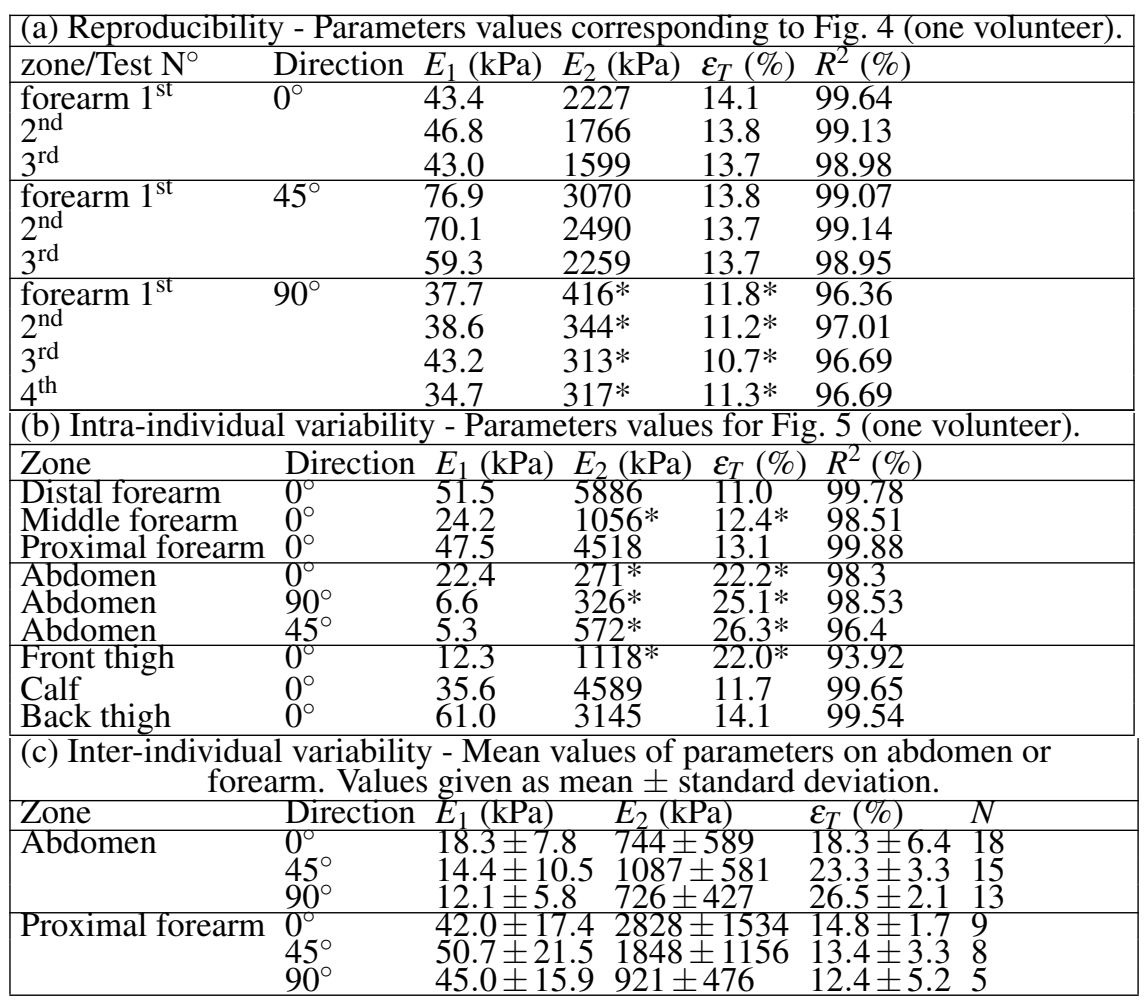

Table 1: Parameters values. The symbol $*$ is used for underestimated values. $N=$ number of tests.

As shown in Fig. 4, three successive full tests have been performed under the same conditions, on the same volunteer, on the same anatomical area (proximal forearm), with three directions $\left(0^{\circ}, 45^{\circ}\right.$ and $\left.90^{\circ}\right)$ and ten minutes between each test. The comparison of obtained results has permitted to evaluate the reproducibility of the test with regard to the variability of the skin tissue. The experimental device has been unglued only when the direction of extension has been changed. Except for the $90^{\circ}$-tests where the final phase has not been reached, $E_{2}$-values steadily decrease with the test number.

\subsection{Intra-individual variability}

Stress-strain curves in Fig. 5 have been obtained on different anatomical areas for the same volunteer. These areas are the three parts of the forearm (distal, middle and proximal), three parts of the leg (posterior thigh, anterior thigh and calf) and the abdomen (Fig. 2). The results highlight the large variability associated with the different anatomical zones and directions of extension. For three neighboring areas on forearm, the $E_{2}$-variability (see Table $1 b$ ) is large. In 


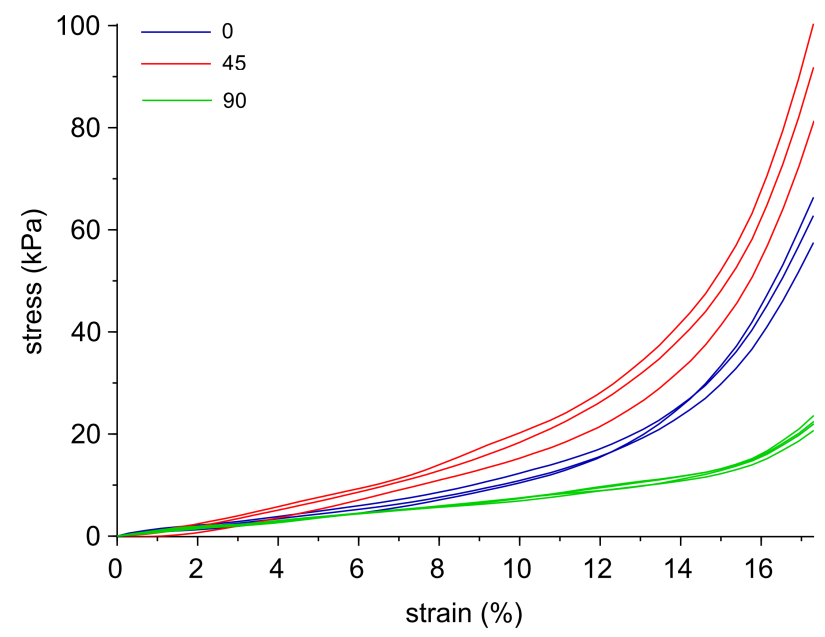

Figure 4: Reproducibility phenomenon for the same volunteer, on the same forearm zone, with ten minutes between each test and three directions $\left(0^{\circ}, 45^{\circ}\right.$ and $\left.90^{\circ}\right)$. See Table 1 a for the corresponding values of $E_{1}, E_{2}, \varepsilon_{T}$ and $R^{2}$.

addition, for the abdomen, the $\varepsilon_{T}$-values are much higher than the values on the forearm that are below $15 \%$. This is observed despite on the abdomen, the loading has been interrupted before reaching the final phase of stress-strain curve, leading therefore to underestimated values of $E_{2}$ and $\varepsilon_{T}$ for this zone. It should be noticed that the front thigh $E_{2}$-value (22\%) is much larger than the back thigh one (14\%). Note that these tests were performed with a straight leg (Fig. 2).

\subsection{Anisotropy consideration}

Table 1c-d summarizes the mean values and the corresponding standard deviation of the physical parameters $E_{1}, E_{2}$ and $\varepsilon_{T}$ for three loading directions on abdomen and proximal forearm, respectively. Note that the mean value and the standard deviation of $E_{1}$ (respectively, $E_{2}$ ) are of the same order, which demonstrates the high variability and the need for a patient-specific approach to predict the mechanical behavior of the skin in vivo.

In regard to the tests on abdomen Table 1c, we note that the maximum stiffness is obtained the most frequently for $45^{\circ}$-direction. However, the maximum stiffness is found for $90^{\circ}$-direction in one test among fourteen, and $0^{\circ}$-direction in three tests among fourteen. Moreover, the mean value of physical parameters (Table 1c) is highly dependent on the direction of extension. Some authors explain that the direction of maximum stiffness depends on the direction of collagen fibers. These works are attributed to the pretension analysis by punching [27, 28] or by observing 


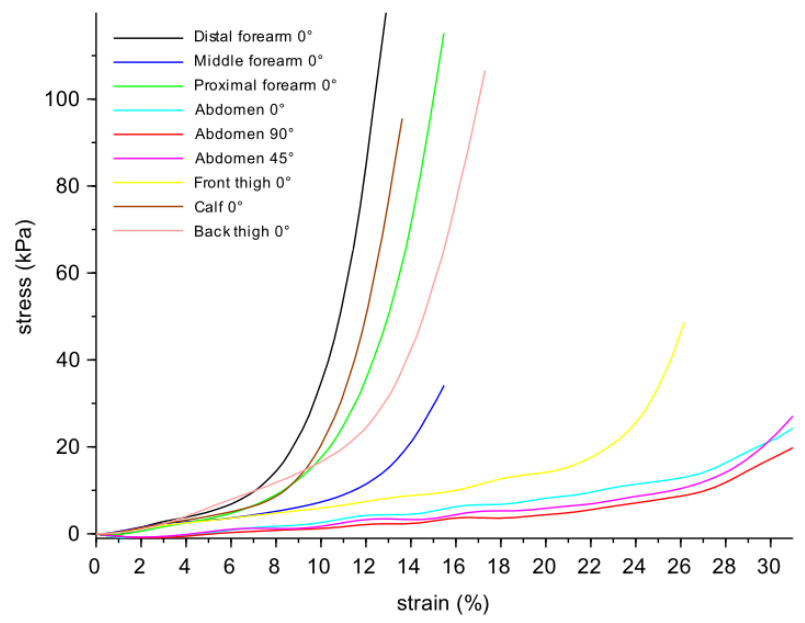

Figure 5: Intra-individual variability observed on the same volunteer for different anatomical zones and extension directions $\left(0^{\circ}, 45^{\circ}\right.$ and $\left.90^{\circ}\right)$. See Table $1 \mathrm{~b}$ for the corresponding values of $E_{1}, E_{2}, \varepsilon_{T}$ and $R^{2}$.

the wrinkles [3]. Our work agrees with [29], and differs from [28] about the assumption that the maximum stiffness is systematically reached for $0^{\circ}$-direction (medio-lateral).

A similar analysis on the leg and on the forearm shows that the direction of maximum stiffness is, approximately, evenly distributed among the three directions $\left(0^{\circ}, 45^{\circ}\right.$ and $\left.90^{\circ}\right)$. For the proximal forearm (Table 1d), the $E_{2}$-parameter is about three times greater for $0^{\circ}$-direction than for $90^{\circ}$-direction. Note that the test at $45^{\circ}$-direction with the smallest value of $\varepsilon_{T}$ belongs to the results with the greater values of $E_{2}$. For the front thigh area, the $E_{1}$-parameter is nearly three times larger for $45^{\circ}$-direction than for $0^{\circ}$-direction. The differences in the $\varepsilon_{T}$-value reach a factor of two when compared with these two directions of extension. Thus, these results confirm that the human skin behavior is anisotropic and emphasize an inter-individual variability as discussed in the next section.

No histological analysis has been carried out on the mechanically-tested skin tissues in the present study, the link between the anisotropy of the cutaneous tissue and its microstructure of fibers networks is not denied : Indeed, the preferential fibers direction in the skin results from not only functional constraints in the concerned zone but also the particular loading history of the material and its environment.

The results in Fig. 6a reveals a large difference between the mechanical behavior of front 


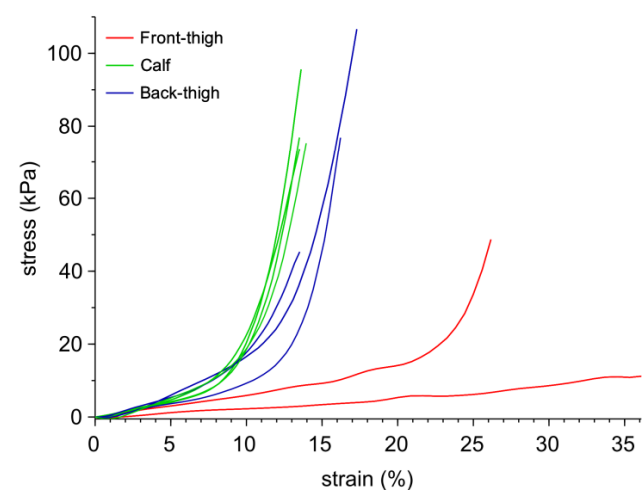

(a) Angle of $0^{\circ}$ from $x$-axis (5 volunteers).

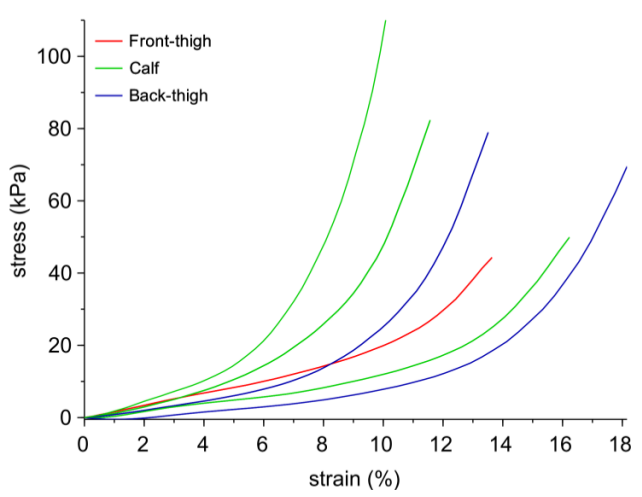

(b) Angle of $45^{\circ}$ from $\mathrm{x}$-axis (4 volunteers).

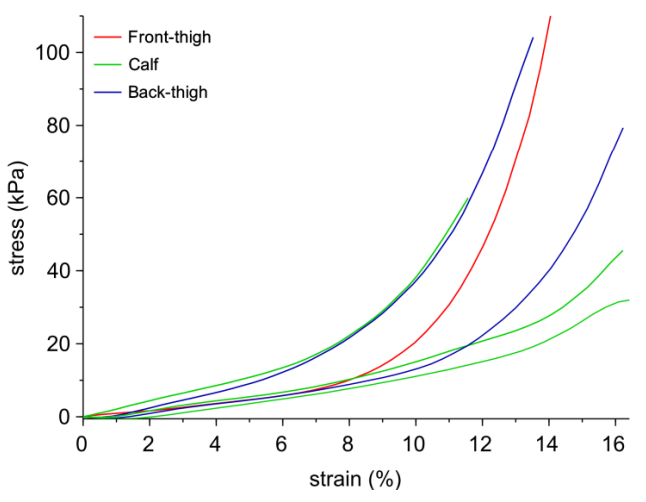

(c) Angle of $90^{\circ}$ from $\mathrm{x}$-axis (4 volunteers).

Figure 6: Extension tests on the leg. 
thigh versus both back thigh and calf concerning the strain threshold $\varepsilon_{T}$ in particular and the transitional phase between low and high stresses. The same is true for $E_{1}$-value which is much smaller at $0^{\circ}$-direction on front thigh area than at other directions. The stress levels measured on front thigh at $0^{\circ}$ do not exceed $55 \mathrm{kPa}$, even though they reach $100 \mathrm{kPa}$ on calf and back thigh. These observations are not true at $45^{\circ}$-direction (Fig. 6b) or at $90^{\circ}$-direction (Fig. 6c). The $0^{\circ}$-direction is also the one for which the leg may be stretched out or tucked under, extending the skin area just above the knee as a reserve supply of skin, wrinkled/unwrinkled when straight/bent. This functionality is not necessary for $45^{\circ}$ - and $90^{\circ}$-directions, and the mechanical behavior is quite similar for close areas.

\subsection{Inter-individual variability}

As shown by [14] and [13], a large variability of skin mechanical properties has been observed for the same anatomical site of several volunteers regardless of the gender, the age and the body mass index (BMI) [30]. Similarly, we have noticed a large inter-individual variability on abdomen, on forearm and on leg (Fig. 6). The resulting values of the physical parameters displayed in Fig. 7 exhibit this variability for men and women between 18 and 52 years old. The BMI-values are ranging between 19 and 26.7. No correlation between BMI-value and physical parameters has been noticed. As illustrated in Fig. $7 \mathrm{c}$, the $\varepsilon_{T}$-value tends to increase with the age especially for the men. In addition we observe a downward trend of $E_{1}$-value with age whatever the gender as also reported by [18]. The $E_{1}$-values range between 5 and $35 \mathrm{kPa}$, the $E_{2}$-values between 500 and $2000 \mathrm{kPa}$ and the $\varepsilon_{T}$-values between 17 and 27\%. Fig. $7 \mathrm{~b}$ do not show any relationship with sex and age. This inter-individual variability also occurrs on the other sites (forearm and leg), whatever the direction.

\section{Conclusion}

This article combines the experimental results of uniaxial extension tests performed on different anatomical sites for numerous volunteers and several directions. These tests have been carried out with a servo-controlled homemade extensometer. This ultra-light and portable experimental extensometer is an efficient device to lessen the influence of the surrounding skin on the measurement and to approximate a classical uniaxial tensile test. This enables to obtain stress-strain curves without assuming an a priori behavior law. 

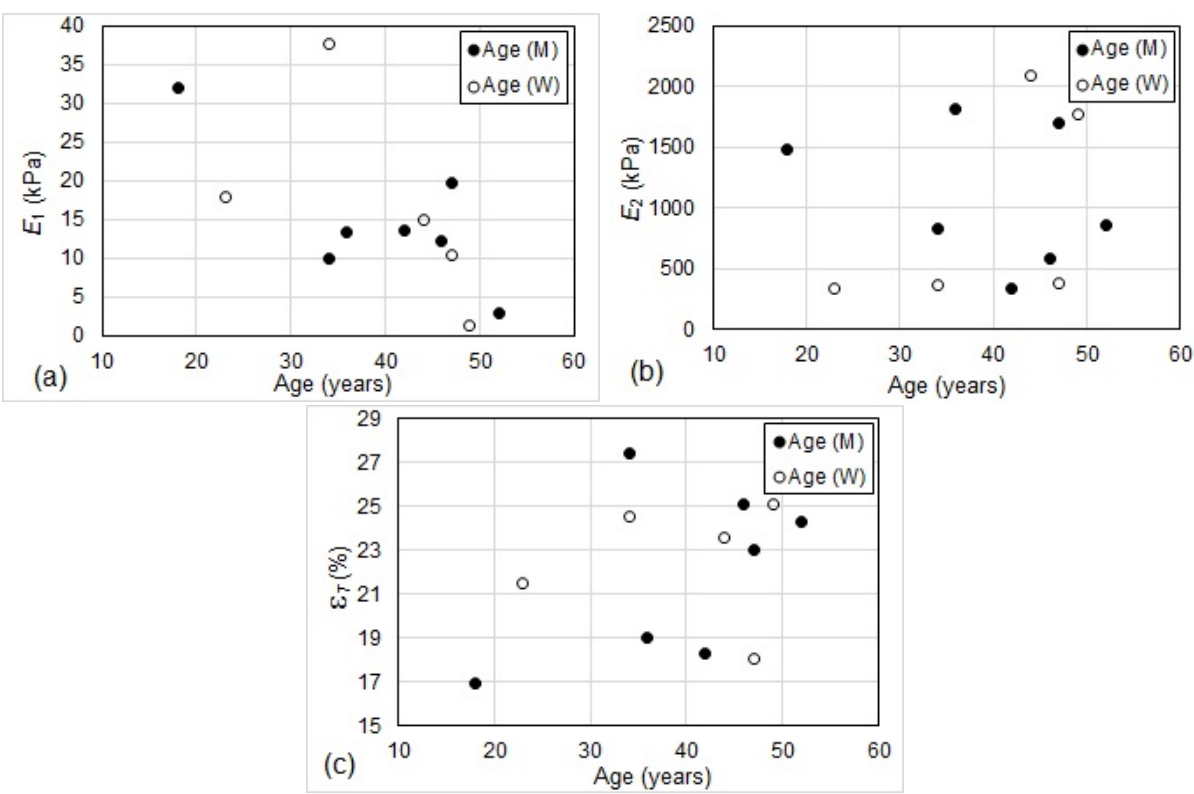

Figure 7: Physical parameters values for abdomen sites of men (M) and women (W). Influence of age on $E_{1}(\mathrm{a}) ; E_{2}$ (b); $\varepsilon_{T}$ (c).

The phenomenological exponential model is used to determine the mechanical parameters of the intrinsic behavior. A good fit between the exponential equation and experimental measurements is obtained provided that the loading reaches the final phase of skin behavior. By using inverse method, three physical parameters useful for the surgeon can be identified:

- The initial tangent modulus $E_{1}$ corresponding to the slope of the stress-strain curve at low strain levels in the initial phase. This modulus is interpreted by various authors as elastin modulus, whereas the collagen fibers are not highly mechanically-stressed by extension and therefore does not yet oppose the deformation.

- The final tangent modulus $E_{2}$ obtained for high levels of strain in the final phase of the stress-strain curve when collagen fibers are associated with elastin fibers to resist deformation. This modulus results from the combination of collagen and elastin fibers.

- The strain threshold $\varepsilon_{T}$, as obtained by the intersection of the tangent to the stress-strain curve at the final phase with the abscissa of strain. This threshold value in the transitional phase can be interpreted as a level of strain achieved when the major part of the collagen fibers are aligned in the direction of extension and begin to resist deformation. This strain 
threshold, which refers to the concept of skin extensibility, is a useful indicator for planning surgery to avoid increasing tensions in the skin tissue and prevent medical complications.

Note that some tests have been analyzed even if the final phase of stress-strain curve has not been reached. In such cases, the corresponding final tangent modulus has been underestimated and consequently the strain threshold has been slightly underestimated too. From the medical point of view, this weak discrepancy in the $\varepsilon_{T}$-value does not present any risk to the patient. If a personalized numerical simulation of surgical operations is aimed, the experimental characterization of the tissue must cover a large range of strain in order to obtain reliable parameters. Moreover, a multiaxial characterization should be undertaken to improve such an approach. From a mechanical point of view, the tests undertaken within this paper demonstrate the benefit of the direct analysis of measurements and the adaptation of loading to reach the final phase of the mechanical behavior in order to obtain the physical parameters representative of the skin behavior. This allows to combine direct measurements of the mechanical properties soft tissues with patient-specific computational methods developed in computed-assisted surgery.

\section{Acknowledgements}

We thank all the volunteers who participated in the tests and the Centre for Studies and Research on the Integument of the Regional University Hospital Center of Besançon for allowing us to perform the dermis thickness measurements. We are thankful to Eric Joseph and Djamel Remache. This work was supported by European Union FEDER grant from Région de FrancheComté, France $\left(\mathrm{N}^{\circ}\right.$ 36381). The authors would like to warmly thank Marine Lévêque for the graphical drawing corresponding to Fig. 2.

\section{Conflict of interest statement}

No conflict of interest.

\section{References}

[1] Pauchot J, Servagi S, Laveaux C, Lasserre G, Tropet Y. Bilateral latissimus dorsi V-Y musculocutaneous rotation flap for closure of a large dorsal radionecrosis. Geometric analysis and interest. About one case. Ann Chir Plast Esthét 2010;55:66-70.

[2] Remache D, Chambert J, Pauchot J, Jacquet E. Numerical analysis of the V-Y shaped advancement flap. Med Eng Phys 2015;37:987-994.

[3] Borges AF, Alexander JE. Relaxed skin tension lines, Z-plasties on scars, and fusiform excision of lesions. Br J Plast Surg 1962;15:242-254. 
[4] Waldorf JC, Perdikis G, Terkonda S. Planning incisions. Oper Tech Gen Surg 2002;4:199-206.

[5] Larrabee Jr WF, Galt JA. A finite element model of skin deformation III. The finite element model. Laryngoscope 1986;96:413-419.

[6] Gambarotta L, Massabò R, Morbiducci R, Raposio E, Santi P. In vivo experimental testing and model identification of human scalp skin. J Biomech 2005;38:2237-2247.

[7] Flynn C. Finite element models of wound closure. J Tissue Viability 2010;19:137-149.

[8] Capek L., Jacquet E., Dzan L., Simunek Antonin. The analysis of forces needed for the suturing of elliptical skin wounds. Med Biol Eng Comput 2012;50:193-198.

[9] Ní Annaidh A, Bruyère K, Destrade M, Gilchrist MD, Otténio M. Characterization of the anisotropic mechanical properties of excised human skin. J Mech Behav Biomed Mater 2012;5:139-148.

[10] Groves RB, Coulman SA, Birchall JC, Evans SL. An anisotropic, hyperelastic model for skin: Experimental measurements, finite element modelling and identification of parameters for human and murine skin. $\mathrm{J}$ Mech Behav Biomed Mater 2013;18:167-180.

[11] Jacquet E, Joly S, Chambert J, Rekik K, Sandoz P. Ultra-light extensometer for the assessment of the mechanical properties of the human skin in-vivo. Skin Res Technol 2017; 00:1?8. https://doi.org/10.1111/srt.12367.

[12] Ryu HS, Joo YH, Kim SO, Park KC, Youn SW. Influence of age and regional differences on skin elasticity as measured by the Cutometer. Skin Res Technol 2008;14:354-358.

[13] Flynn C, Taberner A, Nielsen P. Measurement of the force-displacement response of in vivo human skin under a rich set of deformations. Med Eng Phys 2011;33:610-619.

[14] Boyer G, Laquièze L, Le Bot A, Laquièze S, Zahouani H. Dynamic indentation on human skin in vivo: ageing effects. Skin Res Technol 2009;15:55-67.

[15] Reihsner R, Balogh B, Menzel EJ. Two-dimensional elastic properties of human skin in terms of an incremental model at the in vivo configuration. Med Eng Phys 1995;17:304-313.

[16] Fung YC. Biomechanics: mechanical properties of living tissues. Springer Science \& Business Media; 1993.

[17] Gustafsson F. Determining the initial states in forward-backward filtering. IEEE Trans Signal Process 1996;44:988992.

[18] Wijn PFF. The alinear viscoelastic properties of human skin in vivo for small deformations. PhD thesis, Catholic University of Nijmegen, The Netherlands; 1980.

[19] Fung YC. Stress-strain-history relations of soft tissues in simple elongation. in Biomechanics: Its Foundations and Objectives, (Fung YC, Perrone N, Anliker M., eds.) Prentice-Hall, Englewood Cliffs; 1972:181-208.

[20] Raghavan ML, Webster MW, Vorp DA. Ex vivo biomechanical behavior of abdominal aortic aneurysm: Assessment using a new mathematical model. Ann Biomed Eng 1996;24:573-582.

[21] Levenberg K. A method for the solution of certain non-linear problems in least squares Quart Appl Math 1944;2:164-168.

[22] Marquardt DW. An algorithm for least-squares estimation of nonlinear parameters. J Soc Ind Appl Math 1963;11:431-441.

[23] Daly CH. The biomechanical characteristics of human skin.PhD thesis, University of Strathclyde, United Kingdom; 1966.

[24] Brown IA. A scanning electron microscope study of the effects of uniaxial tension on human skin. Br J Dermatol 1973;89:383-393.

[25] Gibson T, Stark H, Evans JH. Directional variation in extensibility of human skin in vivo. J Biomech 1969;2:201204.

[26] Millington PF, Gibson T, Evans JH, Barbenel JC. Structural and mechanical aspects of connective tissue. in Advances in Biomedical Engineering, (Kenedi RM. , ed.) Academic Press, London and New York; 1971;1:189-248.

[27] Langer K. On the anatomy and physiology of the skin: I. The cleavability of the cutis. Br J Plast Surg 1978;31:3-8.

[28] Cox HT. The cleavage lines of the skin. Br J Surg 1941;29:234-240.

[29] Groves RB. Quantifying the mechanical properties of skin in vivo and ex vivo to optimise microneedle device design. PhD thesis, Cardiff University, United Kingdom; 2012.

[30] Henry F, Piérard-Franchimont C, Pans A, Piérard GE. Striae distensae of pregnancy. An in vivo biomechanical evaluation Int J Dermatol 1997;36:506-508. 